\title{
"LA LAGARTIJA DE LA PANZA BLANCA" DE YOLANDA OREAMUNO: UNA LECTURA DESDE LA VOZ NARRATIVA
}

\author{
Virginia Caamaño Morúa
}

\begin{abstract}
RESUMEN
En el presente artículo se establece un diálogo entre el cuento de Yolanda Oreamuno y tres de sus ensayos, con el fin de señalar la coherencia de la propuesta ética y estética de la autora costarricense. Palabras clave: Yolanda Oreamuno, literatura costarricense, narrativa vanguardista.
\end{abstract}

\begin{abstract}
This article establishes a dialogue between Yolanda Oreamuno'short story and three of her essays in order to point out the coherence of costarrican author's ethic and aesthetic vision. Key words: Yolanda Oreamuno, Costa Rican Literature, Vanguardist Narrative.
\end{abstract}

(...) el mito de Yolanda Oreamuno no existe: lo que existe, perenne y renovado siempre, es su obra (...) Alfonso Chase

Durante muchos años, la institución literaria en Costa Rica guardó silencio sobre la obra de Yolanda Oreamuno. La actitud crítica de que esta escritora hizo gala, ante lo que percibía como faltas e hipocresía de la gente del país le acarrearon pocas simpatías, mientras que su conducta, muy libre, al tratarse de una mujer costarricense en un medio tan provinciano y cerrado, llevó a que fuera su vida "mitologizada" y no su obra, los que captaran la atención de las élites culturales. Durante la misma época y también en Latinoamérica, otras mujeres

\footnotetext{
Virginia Caamaño Morúa. Profesora de la Facultad de Filología, Lingüística y Literatura. Universidad de Costa Rica. San Pedro, San José, Costa Rica.

Correo electrónico: vcaamano@yahoo.com
}

Recepción: 17- 9- 2008

Aceptación: 23- 10- 2008 
escritoras vivían situaciones similares por el hecho de pensar, hablar y actuar a pesar de todas las censuras establecidas. Tales son los casos, entre otras, de Alfonsina Storni en Argentina y Julia de Burgos en Puerto Rico.

Señala Alfonso Chase, en el "Prólogo" de Relatos escogidos (1977) de la autora, que no es sino hasta 1961 cuando Lilia Ramos, Enrique Macaya y Julián Marchena logran reunir en el volumen $A$ lo largo del corto camino un grupo de ensayos y cartas de lo que se ha llamado "su literatura dispersa", publicada en periódicos y revistas, principalmente en Repertorio Americano. Posteriormente, la crítica se fue interesando cada vez más en su obra, hasta llegar a establecer a Oreamuno como una de las fundadoras de la narrativa costarricense contemporánea, no sólo por introducir nuevas técnicas, propias de los movimientos de vanguardia, sino también por los temas escogidos y la manera de tratarlos.

La crítica extranjera, igualmente, comenta el aporte de Yolanda Oreamuno en términos muy elogiosos. Así se puede comprobar en Historia de la literatura hispanoamericana, sexta edición de 1974, donde Enrique Anderson Imbert dice al referirse a la literatura costarricense que "[e]n el lado más subjetivo, y con estilo de más complejidad, se distinguió Yolanda Oreamuno (1916-1956), que representa sus experiencias del tiempo con técnicas del fluir psíquico en Tierra firme y en La ruta de su evasión" (Anderson 1977: 368).

El estudioso colombiano Isaías Peña, en Manual de la literatura latinoamericana, tercera edición de 1992, afirma que:

\begin{abstract}
1949 no fue menos importante en este despegue de la narrativa latinoamericana hacia la concreción de lenguajes más ajustados y composiciones argumentales más coherentes y armónicas: Borges publicó sus cuentos de El Aleph, YolandaOreamuno (Costa Rica, 1916-1956) La ruta de su evasión, Miguel Ángel Asturias Hombres de maíz, y Alejo Carpentier dio el salto, previsto en algunos cuentos anteriores, con su segunda novela El reino de este mundo, en la cual anunciaba sus nuevas experiencias con lo real maravilloso (Peña 1992: 218-9).
\end{abstract}

Por su parte, la crítica puertorriqueña Luz Ivette Martínez asegura que Yolanda Oreamuno:

\begin{abstract}
[...] vislumbró la literatura como búsqueda de valores trascendentes [...]. Llegó a establecer que el oficio literario debería aportar un mensaje de profundo contenido. [...] manifiesta su preferencia por una literatura más acorde con la época, libre del fenómeno de limitación territorial” por lo que "condenó el abuso del costumbrismo que se había desencadenado en un ambiente popular y en un folklore que le restaba autenticidad al movimiento y a la obra" (Martínez 1987: 56).
\end{abstract}

Es precisamente a partir de estos comentarios de Martínez que se hará un acercamiento a una de sus primeras narraciones, "La lagartija de la panza blanca", publicada en Repertorio Americano en 1936, cuando la autora tenía apenas 20 años. Se propone establecer un diálogo entre el relato y tres de sus ensayos, titulados : ¿Qué hora es? ("Medios que usted sugiere al Colegio para librar a la mujer costarricense de la frivolidad ambiente")" y "El ambiente tico y los mitos tropicales" ambos de 1938, así como "Protesta contra el folklore" de 1943, todos publicados también en el Repertorio Americano, con el fin de señalar las propuestas estética y ética, ambas de gran coherencia y profundidad en la obra de Oreamuno. Por medio de ese encuentro entre el relato y los ensayos, se evidencia la afirmación de Roland Barthes, cuando dice que

\footnotetext{
la escritura es una realidad ambigua: por una parte nace, sin duda, de una confrontación entre el escritor y su sociedad; por otra, remite al escritor, por una suerte de transferencia trágica, desde esa finalidad social hasta las fuentes instrumentales de su creación. No pudiendo ofrecerle un lenguaje libremente consumido, la Historia le propone la exigencia de un lenguaje libremente producido (Barthes 1992: 24).
} 
En virtud de esa confrontación entre la escritora y su sociedad y de la necesidad de aquella de expresarse mediante un cierto lenguaje, se plantea la posibilidad de apreciar en el texto de Oreamuno lo que Barthes llama una "escritura en alta voz":

[...] sostenida no por las inflexiones dramáticas,las entonaciones malignas, los acentos complacientes, sino por el tono de la voz, que es un mixto erótico de timbre y de lenguaje y que como la dicción puede ser también la materia de un arte: el arte de conducir el cuerpo [...] (Barthes 1996:108).

Aunque el autor francés propone este tipo de escritura como inexistente por no practicada, algunos de los rasgos que señala como propios de ella parecieran estar presentes en el relato que se comenta. Su apreciación en todo caso, queda en poder del lector y es desde ese lugar que se realiza este acercamiento. El singular "tono de voz" al cual se refiere Barthes es posible percibirlo en la voz narrativa, la cual ocupa un destacadísimo lugar, a un nivel casi protagónico dentro del relato. Su intenso tono vocal se impone como guía de quien al leer también escucha y casi le es posible "percibir" su gesticulación, su presencia material, su corporeidad. Por medio de sus intervenciones constantes, que van más allá del simple relatar, denuncia una serie de valores dominantes, establecidos tanto en la literatura como en las costumbres de la época. Es una voz que se advierte por momentos firme y enérgica, para luego percibirse apenas sugerente o juguetona.

\section{Lo que cuenta el cuento}

El argumento del relato inicia señalando la existencia de una dama que "dicen" que existió y que en algún momento escondió a Morazán en una cueva. Ella se encuentra en mala situación económica y teme que esto imposibilite un buen matrimonio para sus hijas. El relato es señalado desde el título -aunque entre paréntesis- como un "cuento para hombres-niños de imaginación grande". La dama, llamada doña Anacleta, acude, así, sin más explicación, donde un ermitaño que vive en una cueva en Tres Ríos, al cual le solicita ayuda. Este hombre, muy flaco y muy bueno, es ayudado a su vez por ángeles blancos, quienes lo iluminan y le indican el camino que debe seguir. El ermitaño toma entre sus manos una lagartija verde, que al pasar a las de la creyente señora se convierte en una valiosísima joya, toda cubierta de esmeraldas. Luego, doña Anacleta corre donde el avaro, quien le ofrece una suma tan grande de dinero que le parece demasiado. El hombre se limita entonces a despojar a la lagartija de las esmeraldas que estaban en la parte de abajo, en su panza, dándole a cambio una respetable cantidad de dinero a doña Anacleta. La mujer soluciona su situación, casa a sus hijas y devuelve la lagartija al ermitaño. Este la coloca de nuevo en el suelo de la cueva, de donde la había tomado y el animalito camina alejándose. Desde "aquel tiempo", esas lagartijas tienen la panza blanca.

De un argumento tan sencillo, surgen una serie de reflexiones que conducen a indagar sobre varios asuntos, algunos de ellos muy vigentes en la actualidad. Estos permiten valorar la madurez y profundidad del pensamiento de Oreamuno, alcanzado a tan corta edad y la forma en que lo plasma y lo relaciona en su creación literaria, en los distintos géneros en los que incursionó. Se aprecia la eterna confrontación de los seres humanos entre el ser y el parecer, la cual, en el relato, se desarrolla a partir de la posición que se ocupa en la sociedad, como consecuencia de una determinada situación económica y de género. Por medio de la voz narrativa el lector se va enterando del estado de angustia y temor que vive doña Anacleta y su creencia de que sólo la realización de un milagro podría salvarla de las desgracias que presiente. La protagonista es una mujer empobrecida, quien desea proteger a sus hijas del 
acecho de ciertos peligros, muy específicos, pero apenas sugeridos por la voz narrativa, quien descarga en el lector la responsabilidad de interpretar esa vocalización donde se percibe duda o tal vez pudor. Lo que es indudable es el corte que efectúa y le impide enunciar tales peligros más directamente.

La oposición ser/parecer permite contrastar la descripción del sitio donde ocurre la historia versus la localización literaria tradicional para un cuento de esta índole; así como comparar a dos personajes, el ermitaño y el avaro, con base en unos pocos rasgos, destacados muy intencionalmente por la voz narrativa. Para finalizar este acercamiento parcial al texto y en virtud de una serie de características que se pueden identificar, se indagará en cuanto al género en que el mismo se podría inscribir y que ha sido determinado como cuento desde la dedicatoria.

\section{Una voz autoafirmada}

Como se señaló, la voz narrativa, desde el inicio, establece su presencia tomando un rol protagónico. Es a ella a la que se tiene que escuchar, pues es quien sabe lo que ocurre y cómo ocurre, porque a su vez a ella le han contado. De ahí el "dicen” inicial que remite a la tradición oral y una constante intervención subjetiva, evidenciada en la manifestación de opiniones, juicios de valor y disgresiones:

\footnotetext{
Dicen que había una vez doña Anacleta. Doña Anacleta dicen que escondió a Morazán. En una cueva. Así negra, seguramente grande, con pedruzcos enormes. En el corazón de una montaña. Porque las montañas tienen corazón; de eso estoy segura; de lo que no estoy segura es de conocer a doña Anacleta y mucho menos a Morazán (Oreamuno 1977: 45).
}

La voz narrativa, identificada por su discurso como femenina, muy enfáticamente señala que la cueva se encuentra en Tres Ríos y no en Guanacaste. Se expresa cansancio e irritación en ella, ante el discurso folklórico tradicional de la Costa Rica de la época, cuyo estereotipo exige ubicar todo lo típico en Guanacaste o proveniente de ahí. Claramente rechaza esa construcción como la única válida e insiste, al exteriorizar su opinión y tomar el control, cuando afirma con autoridad: "La cueva desgraciadamente está en Tres Ríos y no en Guanacaste. Tenemos el hábito de buscar todo lo bonito, todo lo pictórico y típico en Guanacaste; pero yo lo siento mucho: la cueva está ciertamente en Tres Ríos" (Oreamuno 1977:45).

El lector casi puede "verla" gesticular cuando rotundamente dice "yo lo siento mucho", mientras la materialidad de su presencia a partir de su tono de voz continúa cuando compara ambos lugares. Indica que si bien son diferentes y en los alrededores de la cueva, en Tres Ríos no hay llanuras, en cambio: "hay árboles azules con el tronco morado y hay montañas, sí, seguramente. Y hay bonitos rincones de sombra y caminitos pincelados sobre el pasto" (Oreamuno 1977: 45). De lo dicho se deduce que existen otros sitios en el país que presentan paisajes hermosos, dignos de ser tomados en cuenta y descritos en la literatura.

La posición de Oreamuno en relación con la aplastante utilización del folklore, que según ella lleva a la decadencia de la literatura, la había manifestado tangencialmente en "El ambiente tico y los mitos tropicales" , y ya directamente en "Protesta contra el folklore". No es sólo el paisaje lo que debe interesar al escritor, acota Oreamuno, sino la unión de aquel y del ser humano: "y allí en el paisaje y en el hombre en conjunción de dolor y movimiento, lo autóctono nos llama. Es un camino. Hay muchos abiertos en perspectiva" (Oreamuno 1999: 19). Y de esto trata el relato: de una situación de sufrimiento vivida por la protagonista, que tiene como marco un paisaje, hermoso, pero éste no es lo fundamental de la narración. 
La historia que se cuenta es ubicada en "esos tiempos", sin embargo, no en un pasado atemporal, in illo tempore, cuando sucedieron todas las actividades arquetípicas (cfr. Eliade 1972: 352), sino en un tiempo histórico, en vista de que doña Anacleta no sólo es contemporánea de Francisco Morazán, sino que "dicen" que lo escondió en una cueva. Por lo tanto podría remontarse alrededor de 1840 a 1842, año en que Morazán es fusilado en Costa Rica. Aunque la voz narrativa da al lector libertad para situarla en la época que más le guste, sobre todo a partir de la vestimenta con que puede imaginar a la protagonista, surge en este momento del relato un comentario nada gratuito, precisamente a partir del vestido cuando dice: "Ahora caigo en la cuenta de que la señora como vino a menos, debió usar primero crinolina y tontillo y luego camisa de gola. Bueno, no importa" (Oreamuno 1977: 46).

Pero sí importa, el tono con que hace el comentario implica que no, ya no se puede imaginar el lector a doña Anacleta como se le ocurra, no es posible. Si es una señora que tuvo medios de fortuna y ahora está "venida a menos" no debe -o no puede- usar ropa de señora rica si ya no lo es; "la vestimenta no expresa la persona sino que la constituye", sostiene Roland Barthes (Barthes 1992: 237) coincidiendo con la voz narrativa.

Pero lo más serio, lo que más preocupa a doña Anacleta son sus hijas. Su pobreza impide que ellas tengan la posibilidad de encontrar un "buen marido". Ellas son "lindas y así... dulzonas, lechosas” (Oreamuno 1977: 46) y las rondan a caballo y les cantan serenatas, pero no es probable que un hombre las pida en matrimonio. Por eso, la intencionalidad en el tono de la voz narrativa se manifiesta en la tirada de frases con que dice que la congoja que se vive no es sólo económica, va mucho más allá: "No había plata en la casa. Su equilibrio moral... Bueno, su equilibrio moral amenazaba. Ya se ve" (1977: 46). Se deja ver que la existencia de esa Costa Rica construida desde el principio de los tiempos como "igualitaria", es uno de los "mitos tropicales" a los que se refiere Oreamuno en su ensayo de 1938, en donde denuncia la hipocresía, la falta de solidaridad y los distingos de clase social que separan a los costarricenses. La unión del poder del dinero con la moralidad -y en este caso, con la sexualidad- tampoco es gratuita e incita a cuestionar, además, la clasificación limitante de cuento infantil que se le ha otorgado en algunas críticas.

¿Quiere decir que en "aquel tiempo" una familia con hijas "ñatonas y buenazas", quienes de seguro se repartían todo el oficio de la casa - pues eran hacendosas como debían de ser las mujeres-, pero que no tenían dinero, no eran consideradas esposas dignas por los hombres, en especial cuando éstos gozaban de una buena posición social? Y sin embargo las rondaban y les daban serenatas... las "pretendían". Como cuento infantil, éste que se comenta, vendría a deconstruir el planteamiento y resolución de las situaciones amorosas, propio de los cuentos de hadas. Porque al contrario de lo que sucede en ellos, las hijas de doña Anacleta no sólo debían ser jóvenes buenas y honradas, también tenían que tener medios de fortuna para parecerlo y así acceder al matrimonio.

Dos años después de publicado este cuento, aparece su ensayo conocido bajo el título de “QQué hora es?” , en donde en palabras de Emilia Macaya:

[...] desde una abarcadora visión del "ser" y el "deber ser" de lo femenino, en pugna con el orden patriarcal, [...] Yolanda Oreamuno propone un orden distinto para un nuevo tipo de mujer, libre, completa y plantada de lleno frente al mundo (Macaya 1997:82).

En dicho texto, Oreamuno cuestiona las limitaciones de toda índole que agobian la vida de las mujeres. Ella critica la escasa importancia que se brinda a su educación, lo cual les impide adquirir conciencia de su estatuto de personas al afirmar que "no hay dignidad 
sin conciencia y la suprema conciencia está en asumir con pleno conocimiento de causa las responsabilidades que da la vida al enrolar a un ser en su corriente , sea hombre o sea mujer" (Oreamuno 1999: 46-7).

En relación con la dependencia económica, la llama "forzosa" y lamenta el que las mujeres deban estar sujetas también a la tutela intelectual y moral de los mayores. No es de extrañar que en "esos tiempos" doña Anacleta sufra tanto por sus hijas, por el peligro en que se encuentran, pues su único posible destino es el matrimonio y este no parece viable dadas las prácticas sociales establecidas. Oreamuno se queja, en el ensayo citado, de que " la caza del marido" aparezca como "actividad primordial, consecuencia de la educación recibida en anteriores etapas" (Oreamuno 1999: 56) y recomienda una educación sexual basada en los conocimientos de la ciencia, como el "mejor medio de combatir el 'derecho de pernada' que aún pretenden ejercer los caballeretes" (Oreamuno 1999: 61). He ahí el peligro real que acecha a las hijas de doña Anacleta y que es posible captar gracias a la intervención de la voz narrativa: que alguno de quienes las rondan, "serenatean" y pretenden, exija su derecho de pernada, asunto muy corriente gracias a la tradición patriarcal imperante en la sociedad. Más aún cuando los involucrados son un hombre de medios económicos acomodados y una joven pobre, o para el caso, "venida a menos".

Para evitar esta deshonra en ciernes es que la angustiada señora va a la cueva donde vive el ermitaño, quien seguramente inspirado por los ángeles, le brinda la lagartija verde, convertida en una joya de gran valor. Las apariencias engañan y la mano que el santo alarga es descrita como si fuera "de brujo , flaca y pálida, con grandes uñas como ríos de tierra morena, con tilintes nervios como grandes costuras" (Oreamuno 1977: 46). La transformación de la lagartija ¿fue milagro o magia? Porque el ermitaño tiene características de santo y de brujo según se dice. De cualquier forma, la señora tiene mucha, mucha fe y al extender las manos, se escucha a la voz narrativa enseñar el modo en que las entrelaza para recibir el tesoro, de manera que -casi performativamente- es posible "verla hacer el gesto": "Puso los dedos entrelazados. Así,... Uno sobre el otro y las dos palmas se ahuecaban cascarosas y rajadas, y los ojos miraron el nido hechos despabilamiento de admiración" (Oreamuno 1977: 47).

Doña Anacleta se apresura, con la valiosa joya adonde el avaro, quien es viejo, como el ermitaño. La voz narrativa también se refiere a sus manos. El hombre tiene manos de santo. Pero ¿lo es...?, ¿lo puede ser un avaro? El enfrentamiento entre el ser y el parecer y la manera en que se percibe cada uno de ellos es expuesto magistralmente por la voz narrativa, de un modo muy natural, como si lo hiciera sin darse cuenta de lo que está diciendo. Pero lo dice y el lector lo percibe claramente: de nuevo, las apariencias engañan: quien tiene manos de brujo es un santo, y el de las manos de santo... es un avaro.

Doña Anacleta no ambiciona riquezas materiales, sólo seguridad y una "humilde felicidad" y una vez casadas sus hijas, regresa a la cueva y llena de agradecimiento devuelve la lagartija al santo de las manos de brujo, quien la deposita en el suelo. Ahí, la lagartija camina nuevamente. La voz narrativa dice que cuentan que

desde "aquel tiempo", todas las lagartijas allí en los alrededores de la cueva de piedras grises y musgo verde, por los caminitos de la cuesta de la montaña entre los árboles azules de tronco morado, y por donde la señora subió y por donde la señora bajó, tienen la espalda verde y la panza blanca (Oreamuno.1977: 47-8).

Agrega que quien lo dice es un viejo con manos de brujo y asegura que la historia es verdad. 
La confrontación de la escritora con algunos de los valores dominantes en la sociedad costarricense de su época se evidencia en este relato, realizado -de acuerdo con la lectura propuesta-, por medio de una "escritura en voz alta". Aunque Barthes afirma que ésta es una escritura no practicada, es posible considerar a partir del acercamiento efectuado que "La lagartija de la panza blanca" es un ejemplo aproximado de ese "texto donde se pudiese escuchar [...] la articulación del cuerpo, de la lengua, no la del sentido, la del lenguaje” (Barthes 1996: 109).

\section{Modalidades genéricas}

La narración responde a las características del cuento moderno, definido por los estudiosos como una estructura cuyo fundamento reside en la concisión temática y en la intensidad expresiva, que pone en el texto los máximos recursos de la lengua para revelar la imaginación de un narrador individual (cfr. García Berrio et al. 1992). Pero también es válido acercarlo a otras modalidades dentro del género, en virtud de ciertos rasgos específicos que se pueden identificar en el texto. Como se verá, muy brevemente, a continuación.

Si se observa la conducta de doña Anacleta, persona sin afanes de riqueza, quien no entrega toda la joya a cambio de "una cantidad que se negaba a oír" (Oreamuno 1977: 47), bastándole con muchísimo menos, sería posible hablar, aunque no en forma estricta, de un "apólogo", donde la rectitud moral de la dama sería un ejemplo digno de emulación. El relato permite, hasta cierto punto, el título de "leyenda". La estudiosa Juana Martínez afirma que a ésta: "no le interesa la veracidad histórica y su componente máximo lo constituye de una manera indistinta, la imaginación o la tradición preferentemente de transmisión oral, de modo que puede tanto inventar, como convertir en maravilloso un suceso real" (Martínez 1993: 232).

La oralidad de la historia no deja lugar a dudas. La voz narrativa continuamente hace énfasis en las palabras "dicen que", lo que puede llevar al lector a asumir que desde "esos tiempos", muchas voces han venido contando dichos sucesos, fueran reales o no. Habla también Martínez, de la creación de una atmósfera mágica y de misterio dentro del relato y agrega que por medio de la leyenda, en ocasiones, se explica el origen de creencias o de objetos. "La lagartija" reúne una serie de estos rasgos, como se ha visto a lo largo del trabajo. Gracias a esta historia se tiene conocimiento sobre el origen de la panza blanca en algunas lagartijas verdes, sobre todo aquellas que se encuentran en los alrededores de cierta cueva, ubicada en Tres Ríos.

A partir de la transformación ocurrida a la lagartija; transformación producto de la fe y de la acción del viejo ermitaño, podría llamársele "milagro", el cual según García Berrio y Huerta Calvo: "versa en torno a las admirables acciones salvadoras realizadas por un santo" (1992:175). Desde nuestra lectura, el poder demostrado por el ermitaño y la misma transformación milagrosa son asumidos con aparente naturalidad por la voz narrativa, quien pareciera no cuestionar ese "dicen que" constantemente repetido a lo largo de su recuento de la historia.

Estos hechos dan pie a considerarlo como cuento maravilloso, ya que cumple una de las características propuestas por Todorov para ese tipo de relato: la aceptación de lo inverosímil e inexplicable; así : "Lo maravilloso, al obtener explicación tan sólo en lo sobrenatural no produce ese estado de incertidumbre, pues el lector debe aceptar las cosas tal cual se muestran" (Barella 1994: 12). Y aún más cuando sucedió en "aquel tiempo", cuya lejanía invita a percibirlo como 
algo nebuloso, mítico y alejado de la razón, pues durante su transcurrir "todo es sencillo y arrullón y tembloroso. Así... Bueno..., suave y tranquilo” (Oreamuno 1977: 48), según reitera la voz narrativa. Y sin embargo, doña Anacleta sufría, se sabía indefensa y se preocupaba por sus hijas, a quienes consideraba en peligro. No, no todo era tan bueno, tan suave, ni tan tranquilo. Las prácticas sociales establecidas, tanto en "aquel tiempo" como ahora, producen situaciones de exclusión, marginación e injusticia. Y quién mejor que una escritora de conciencia lúcida para contar ciertas experiencias que seguramente vivieron las mujeres de tiempos pasados, con la esperanza de que llegue el momento en que no se repitan.

De ahí que el paréntesis de la dedicatoria tal vez sea una dirección más de la voz narrativa y debería ser tomada de manera textual: no es un cuento para niños, sino para gente grande con imaginación y espíritu crítico, que deconstruya los tradicionales "mitos tropicales" y no se deje vencer por la apatía o peor aún, por la corrupción moral y social, tan combatidas por Oreamuno. Al concluir este acercamiento parcial al cuento comentado, pareciera pertinente retomar las palabras de la escritora Emilia Macaya, quien en Espíritu en carne altiva, texto dedicado a estudiar la obra de Yolanda Oreamuno desde una perspectiva de construcción de identidad y autoría femeninas expresa que:

\begin{abstract}
la obra entera de Yolanda Oreamuno, aún diseminada y extraviada en parte, es lo que hemos de continuar rescatando, es lo que habremos de seguir construyendo, para poder asegurar así, por esa palabra afirmativa y purificadora, la existencia de un "eterno y por siempre deseado amanecer" al que ella y todos los seres de este mundo, deberíamos tener pleno derecho (Macaya 1997: 130).
\end{abstract}

\title{
Bibliografía
}

Anderson Imbert, Enrique 1974. Historia de la literatura hispanoamericana. II. Época Contemporánea. México: Fondo de Cultura Económica.

Barella, Julia. 1994. "La literatura fantástica en España". Anthropos. Revista de documentación Científica de la Cultura. Marzo- abril: 154-155.

Barthes, Roland. 1992. El grado cero de la escritura. México: Siglo Veintiuno Editores.

1992. "Pierre Loti: Aziyade”. Nuevos ensayos críticos. México: Siglo Veintiuno Editores.

1996. El placer del texto. México: Siglo Veintiuno Editores.

Duch, Lluís. 1998. Mito, interpretación y cultura. Barcelona: Editorial Herder, S.A.

Eliade, Mircea. 1996. Tratado de historia de las religiones. México: Ediciones Era.

García Berrio, Antonio y Javier Huerta Calvo. 1992. Los géneros literarios: sistema e historia. Madrid: Ediciones Cátedra.

Macaya, Emilia. 1997. Espíritu en carne altiva. San José: Editorial de la Universidad de Costa Rica 
Martínez, Juana. 1993. "El cuento hispanoamericano del siglo XIX”. Historia de La literatura hispanoamericana. Tomo II. Del Neoclasicismo al Modernismo. Luis Iñigo Madrigal (coord.). Madrid: Ediciones Cátedra.

Martínez, Luz Ivette. 1987. Carmen Naranjo y la narrativa femenina en Costa Rica. San José: EDUCA.

Oreamuno, Yolanda. 1977. Relatos escogidos. San José: Editorial Costa Rica 1999. El ambiente tico y los mitos tropicales. Heredia: EFUNA

Peña, Isaías. 1992. Manual de la literatura latinoamericana. Bogotá: Educar Editores.

Vallbona, Rima de. 1972. Yolanda Oreamuno. San José: Depto. de Publicaciones del Ministerio de Cultura, Juventud y Deportes. 